\title{
Fórum Social Mundial: Palestra de Celso Daniel na abertura da Reunião Regional Preparatória
}

Claudio Antônio DiMauro ${ }^{1}$

\begin{abstract}
Resumo
O Fórum Social Mundial (FSM) foi, durante muito tempo, uma das maiores referências globais em termos de articulação da reflexão e da prática de movimentos sociais altermundistas. Em novembro de 2001, portanto meses antes de sua morte, o ex-prefeito de Santo André e importante quadro do Partido dos Trabalhadores, Celso Daniel, abriu a Reunião Regional Preparatória para o II FSM em Rio Claro (SP). Com transcrição de Cláudio Antônio Di Mauro (ex-prefeito de Rio Claro), a palestra reúne importante análise daquela conjuntura, bem como a identifica caminhos para análises e abordagens a respeito dos espaços públicos.
\end{abstract}

Palavras chave: Fórum Social Mundial; altermundismo; globalização; Celso Daniel

MANIFESTAÇÃO DO PREFEITO DE SANTO ANDRÉ (SP) CELSO AUGUSTO DANIEL EM RIO CLARO (SP), 21 DE NOVEMBRO DE 2001.

(Palestra gravada e transcrita com revisão pelo autor Celso Daniel)

"Muito bom dia a todos, a todas que vieram nesse seminário preparatório da reunião de autoridades locais do fórum social Mundial, eu cumprimento em particular o Prefeito Cláudio de Rio Claro que é nosso anfitrião e que teve a feliz ideia de realizar este encontro preparatório.

Vou diretamente ao tema aqui, normalmente se é um prefeito que vai falar suponho que o que se espera deve seja falar sobre experiências concretas, talvez não tenha sido a melhor escolha, mas de qualquer maneira eu pensei o seguinte: para fazer contribuições ao Fórum Social Mundial seria fundamental que a ente tivesse condição de fazer conexões entre experiências concretas e uma reflexão um pouco mais ampla a respeito do tema que está posto aqui na mesa. Então eu parto desse ponto, que é de fazer uma reflexão mais ampla considerando o tema Descentralização, Participação e Gestão Local: alcance e limites para o desenvolvimento social e na verdade capturo três temas diferentes articulados. O primeiro, é o tema da Descentralização na sua relação com a

\footnotetext{
1 Professor do Instituto de Geografia da Universidade Federal de Uberlândia.
} 
gestão local e esse tema, a meu juízo, evoca a questão da Federação aqui no Brasil, a questão do nosso pacto federativo. Em segundo lugar, Participação por sua vez, remete ao tema da Gestão Participativa com uma série de desdobramentos que me parecem fundamentais. E em terceiro lugar o Desenvolvimento social combinado com a gestão local fazem, a meu juízo uma referência importante a uma relação que cada vez é mais presente nas cidades, nos locais onde moramos, que é a relação entre a exclusão e a inclusão social. Então eu gostaria de fazer algumas observações a respeito de cada um desses aspectos, porque eles são diferentes embora articulados e em última instância é isso que está sendo proposto como tema para esta mesa.

Para começar, portanto com relação à gestão local, o último tema, desenvolvimento social. Eu quero entender a gestão social como estreitamente vinculada à ideia de uma gestão pública voltada a garantir condições para a inclusão social da maioria da população. E aqui existem questões que deveriam ser abordadas. A primeira delas é a seguinte: na Europa o tema e a nomenclatura exclusão social são algo relativamente recentes, de últimos anos. Porque em última instância a exclusão que muitos desses países e muitas cidades desses países estão vivendo hoje diz respeito exatamente à maneira como se concretizou o processo de globalização. Quer dizer, a maneira do processo de globalização levou ao aparecimento de situações de exclusão, que a rigor não existiam desse modo no período anterior.

No Brasil a questão é mais grave, porque nós temos a superposição dessas novas dimensões (essa nova forma como se apresenta a exclusão social em função dessa globalização desigual), sobre uma exclusão histórica que já tínhamos devido a nossa profunda desigualdade de distribuição de renda, por exemplo. É acentuada também por preconceitos com relação ao gênero, raça e assim por diante. Todo o debate que foi travado, (principalmente durante a década de 70 na América Latina) sobre a marginalidade urbana, não era outra coisa senão aquilo que hoje a gente, legitimamente chama de exclusão social. então trata-se de um tema absolutamente na ordem do dia para nós aqui no Brasil, porque não se trata apenas de consequências diretas e danosas do processo de globalização, mas da conjugação destas com problemas herdados, de exclusão social, extremamente graves que temos em nosso país.

Ao lado disso, faço uma referência ao fato de que essa dialética exclusão e inclusão social envolve inúmeras e diferentes dimensões. Porque uma coisa é você falar de pobreza e remeter a pobreza à falta de emprego. Outra coisa é lembrar que exclusão - inclusão social tem a ver com várias dimensões da vida das pessoas, várias maneiras pelas quais as pessoas se sentem incluídas ou excluídas na sociedade, na comunidade onde vivem. Sem dúvida alguma, a dimensão econômica, o problema do desemprego, a falta de oportunidade de geração de trabalho e renda têm 
centralidade e representam algo absolutamente fundamental. Mas também há exclusão, por exemplo do ângulo social, dos serviços públicos que garantam a cidadania como educação e saúde. Há também a exclusão social vinculada à discriminação: discriminação contra as mulheres, discriminação de gênero em geral, a discriminação de "raça". A Semana da Consciência Negra vem realmente em muito boa hora para resgatar o tema da discriminação racial no Brasil, que muitas vezes fica oculto, colocado "embaixo do tapete".

Mas temos também formas de exclusão tipicamente urbanas. Por exemplo, as nossas cidades são caracterizadas por uma parcela muito grande de espaços e territórios ilegais, clandestinos onde as pessoas não têm condições adequadas de moradia, infraestrutura, nem sequer têm a posse da terra e isso causa uma insegurança tremenda nas pessoas, além de estarem submetidas aos preconceitos daqueles que moram em outros lugares mais valorizados. Uma baixa autoestima, portanto, da comunidade mesmo no âmbito metropolitano, que não é o caso aqui de vocês, mas é o caso aqui de vocês, mas é o caso já, por exemplo, em Campinas. No âmbito metropolitano, normalmente existe um centro metropolitano e existem as periferias metropolitanas e essas cidades periféricas metropolitanas também se veem numa situação de exclusão no outro sentido considerado.

Portanto, há a exclusão propriamente cultural, exclusão não somente de acesso aos bens culturais, ao lazer, à cultura, ao esporte, mas também à exclusão subjetiva, da falta de perspectiva em relação ao mundo, aspectos subjetivos que impactam diretamente na qualidade de vida das pessoas. Não são meramente objetivas, como garantir instrumentos, serviços públicos e assim por diante. Assim, se a exclusão é multidimensional naturalmente faria sentido pensar políticas públicas locais que digam respeito não apenas a setores específicos, mas também uma política de educação, de saúde, uma política de geração de trabalho e renda, uma política cultural e assim por diante. Faria todo sentido nós pensarmos uma integração em torno dessas várias iniciativas, ou seja, a ideia de criar condições para que as pessoas nas nossas cidades possam transitar de uma situação de exclusão que pode envolver uma ou inúmeras dessas dimensões que eu comentei para uma situação de inclusão social.

Isto exige uma verdadeira revolução na maneira de fazermos gestão pública, porque vocês sabem muito bem que, tanto nas prefeituras como no estado o trabalho se apresenta compartimentado. Existem diversas Secretarias que muitas vezes não se conversam direito e é muito difícil fazer trabalhos conjuntos; mas trabalhos conjuntos são fundamentais, porque por um lado, aumentam a eficiência do uso do serviço público, por outro lado permitem melhores resultados de cada um dos programas considerados, por exemplo de saúde, educação, formação 
profissional, incubadora de cooperativas, o microcrédito, alfabetização de adultos, saúde da família, urbanização de favelas e por aí vai. Os resultados deles são muito melhores em termos de qualidade, e mais, com essa ação integrada é possível se pensar numa superação de várias dimensões da exclusão social, com participação direta da sociedade na medida que o processo seja focalizado territorialmente e seja pensado de maneira integrada. Muito de passagem, apenas faço referência ao fato de que nós temos feito um esforço de implementar um programa com qualidade, com essa natureza lá no município de Santo André que é nosso Projeto Integrado de Inclusão Social.

O segundo ponto que quero tratar é o tema da Participação, gestão participativa, ou cogestão pública, junto com a comunidade. Gestão participativa, de verdade, envolve a partilha de poder entre o governo e a comunidade, envolve uma nova concepção de democracia que não se reduz mais apenas à democracia representativa, mas articula a democracia representativa - Câmara Municipal, o governo - com a participação direta da comunidade. Democracia representativa, democracia participativa. Portanto, uma situação completamente diferente com a criação de novas esferas públicas democráticas e novas pessoas, novas personagens, novas lideranças da comunidade têm condições de se expressar e, portanto, expressar o ponto de vista das classes dominadas aqui no Brasil, que tem sido historicamente excluídas do poder político.

Este tema também envolve algumas questões diferenciadas. Há uma questão mais geral que diz respeito ao mundo, que é o desgaste da democracia representativa. Hoje em dia tem decrescido a participação das pessoas nas eleições, mesmo nos países centrais, a classe política e a própria atividade política têm sido desmerecidas, têm cada vez menos prestígio. Isso tem a ver com a perda de prestígio da democracia representativa, da democracia como sistema. Vocês sabem muito bem que a alternativa à democracia é o autoritarismo; a ditadura é o pior dos mundos, é verdade que aqui no Brasil, por exemplo, nós temos uma democracia incompleta. No entanto, é melhor ter uma democracia incompleta, onde é possível lutar para que ela se complemente, do que viver sob uma ditadura, um regime autoritário. Então a perda de prestígio da democracia representativa é um problema sério para quem defende efetivamente a cidadania. Nesse ponto a democracia participativa, a participação direta passa a ser uma referência absolutamente inovadora no sistema político e acreditamos não apenas do Brasil, mas pode ter reflexos inclusive internacionais, mundiais.

A referência mais conhecida evidentemente é o Orçamento Participativo, mas as experiências são mais diversificadas do que isso. O Orçamento Participativo tem ganho um prestígio nacional e internacional muito grande, extremamente importante. Eu queria frisar aqui em função exatamente dessa mudança radical, que ele pode operar na revalorização do sistema 
político, da atividade política e portanto da democracia, não pensada mais como democracia representativa apenas mas como essa articulação entre democracia representativa e democracia direta: Trata-se portanto de uma verdadeira invenção democrática, cuja importância nós não podemos subestimar, uma invenção democrática que tem um ponto de partida extremamente importante aqui no Brasil, com a referência do Orçamento Participativo.

Um outro elemento que eu gostaria de agregar aqui, específico do Brasil, a tendência ao clientelismo, as relações pessoais que depois se traduzem na privatização da coisa pública.

Isto é um problema tremendo porque aqui, muitas vezes, significa por um lado o esvaziamento da esfera pública, ou seja, do debate público sobre os direitos de cidadania, por outro lado significa que as pessoas vão procurar resolver os seus problemas através das relações pessoais, quer dizer, através do clientelismo, de um favor de um político, de uma pessoa importante, ou mesmo de amigos da família e tudo mais. Vai se buscar resolver os problemas gravíssimos que nós temos, através desse tipo de subterfúgio. Naturalmente o que acontece é que as pessoas "quebram o galho", mas isso ajuda a legitimar, aprofunda a concentração de renda e a desigualdade social que existe aqui no país. Então para se contrapor a isso, a participação direta, a co-gestão, a gestão participativa podem ter um papel absolutamente fundamental com a criação de novas esferas públicas democráticas para se revalorizar o espaço onde se discute e onde se conquistam direitos, onde a comunidade conquista direitos que depois têm que ser garantidos pelo poder público, em primeira instância pela gestão local.

É uma herança histórica brasileira, portanto que a gente não deve desconsiderar, ou seja, a participação cidadã é uma resposta concreta à exclusão política, uma outra dimensão da exclusão social e que a maioria de nós vivemos.

Então eu estava falando como resposta a exclusão política e como possibilidade de conquista da cidadania, porque cidadania não se doa, não vai ser um governo bonzinho que vai garantir cidadania para todos. Cidadania se conquista e a possibilidade de as pessoas terem condições de participar das decisões políticas, empunhando a noção de direitos de cidadania, de conquistar cidadania. Eu fiquei muito sensibilizado quando vi anteontem um documentário feito em Santo André sobre hip hop, fiquei impressionado porque a Tata Amaral, que é uma cineasta já hoje conhecida, e diretora desse documentário, buscou ao invés de pessoas conhecidas do hip hop, ela pegou a juventude, gente de 15,16,17, no máximo 18 anos, gente que está começando. Gente que faz um hip hop diferente daquele que estamos acostumados a ouvir com Mano Brown e outros do gênero, que é só contestador. Trata-se de gente que está pensando em alternativa, que contesta, mas que está querendo construir alternativa. E um desses garotos é conselheiro do Orçamento 
Participativo de Santo André, ou seja, ele faz essa atividade cultural de contestação e o documentário mostra ele fazendo o chamamento, a distribuição de panfletos para a garotada, para a galera participar do orçamento participativo. Ou seja, isso daí pode significar esperança em relação ao futuro dessa juventude hoje tão desassistida, através de participação.

O último aspecto que quero comentar é a respeito da Descentralização, que envolve a questão federativa, tema complexo que admite diferentes pontos de vista. Quero apontar que a questão da descentralização é muito polêmica, porque muita gente diz o seguinte: se você descentraliza para a gestão local, mesmo que a descentralização seja com igualdade de recursos econômicos, isso pode aumentar as desigualdades sociais, porque haverá as gestões boas e as gestões ruins, e quem garantirá que não se aprofundarão ainda mais as desigualdades? Por outro lado, com a nossa herança histórica também, tem muita gente conservadora e autoritária, autoritária do tipo Oliveira Viana, que defende a ideia, de que a descentralização em direção à gestão local significa, na verdade, descentralizar o clientelismo, fortalecer o clientelismo e, portanto fortalecer a desigualdade política, a dominação dos grupos, das oligarquias e assim por diante.

Então é evidente que a descentralização tem um aspecto positivo, é fundamental que aquilo que está próximo do cidadão possa ser incorporado com a participação direta do cidadão, da cidadã e que ela esteja próxima, dê conta das especificidades locais. Mas existem esses outros problemas e isso é que nos faz ter que pensar na questão da Federação. Há poucas federações no mundo e o Brasil é uma das poucas existentes, com autonomia municipal inclusive.

Não dá para pensar a descentralização apenas com aumento da autonomia municipal. O Vitor Nunes Leal, que fez um estudo sobre o coronelismo, dizia o seguinte: "a tendência ao governismo dos poderes locais é derivada da falta de autonomia desses poderes locais". Eu acho que ele tem plena razão: mais autonomia é fundamental, mais recursos para gestões locais, para que nós tenhamos condições de implantar localmente programas que são fundamentais. Mas isso é incompleto: precisamos combater desigualdades macrorregionais, das regiões do Brasil, precisamos combater também as desigualdades existentes em microrregiões, em regiões metropolitanas e também pensar um novo pacto federativo, que articule políticas nacionais com operacionalização descentralizada, o que deve envolver participação direta do governo local, inclusive em termos financeiros, a meu juízo, mas deve envolver critérios para evitar exatamente essa questão do clientelismo e das desigualdades. Critérios do tipo, por exemplo, controle social de avaliação de desempenho do uso desses recursos públicos em cada localidade, em segundo lugar critério de participação direta da comunidade como controle público, que é o segundo tema que eu comentei, em terceiro lugar, que se considerem também regras iguais para todos, porque hoje em dia os 
recursos são muito mal distribuídos entre os diferentes municípios e isso pode levar a um aumento das desigualdades. Então isso tudo tem que ensejar uma reformulação do nosso pacto federativo.

Como conclusão, nós estamos aqui diante da questão do Fórum Social Mundial e os problemas da globalização que o Prefeito Cláudio de Mauro estava comentando conosco, que gera desigualdade. E não podemos esquecer que, frente a essa globalização, somos um país periférico e, portanto, dependente. Isso é um grande problema para nós, ao pensarmos a nossa inserção nesse processo de globalização, ou num outro processo de globalização.

Não há dúvidas que temos que ter ações integradas com todas as outras cidades, com todos os outros países, com as organizações não governamentais e com os movimentos sociais. Mas é preciso que também nós façamos, digamos assim, o dever de casa. Aqui no Brasil o que nós precisamos tremendamente é de um projeto de nação, porque só com um projeto de nação autônoma, com uma integração soberana ao processo de globalização, é que nós temos condição de pensar de verdade na inclusão social, no fortalecimento da gestão local. Sugiro a vocês a leitura de uma entrevista do José Luis Fiori (dada à Folha de São Paulo no dia 18 de novembro de 2001) em que ele faz justamente essa referência: é exatamente em momentos de mudanças grandes como essas, que se abrem mais oportunidades para países periféricos como o Brasil para superar sua condição de periferia, mas isso exige, ao mesmo tempo uma redefinição do nosso pacto federativo, mais homogeneidade territorial, uma redefinição do nosso pacto social, combate à exclusão social, políticas que garantam a inclusão social e mais homogeneidade social, em suma esses dois elementos e o terceiro elemento que é mais participação política, um pacto, uma proposta de nação que envolva a articulação entre a democracia participativa e a democracia direta, nos vários níveis de governo, a começar do governo local.

Pessoalmente não tenho dúvida de que um projeto de nação tem que começar a partir do local, da gestão local, mas tem que começar do local, pensando a gestão local nesse contexto mais amplo de uma Federação com todas as dificuldades e particularidades, que a nossa Federação tem, pensando assim eu creio que nós temos condição de repensar esse país, a partir de nossa localidade, do lugar onde nós moramos, do lugar onde nós administramos, no caso dos prefeitos, e repensar. Com isso contribuindo para a construção de uma outra nação, uma nação que seja soberana, que seja independente, que tenha desenvolvimento econômico, mas desenvolvimento sustentável, desenvolvimento igualitário, sem exclusão social e com participação política para todos. Muito obrigado!" 